\title{
Activation of mitogen-activated protein kinases (p38-MAPKs, SAPKs/JNKs and ERKs) by the G-protein-coupled receptor agonist phenylephrine in the perfused rat heart
}

\author{
Antigone LAZOU*, Peter H. SUGDEN $\dagger^{-1}$ and Angela CLERK§ \\ *Laboratory of Animal Physiology, Department of Zoology, School of Biology, Aristotelian University of Thessaloniki, Thessaloniki 54006, Greece, †NHLI Division \\ (Cardiac Medicine), Imperial College School of Medicine, Royal Brompton Campus, Dovehouse Street, London SW3 6LY, U.K., and §Division of Biomedical Sciences, \\ Imperial College School of Medicine, Charing Cross Campus, Fulham Palace Road, London W6 8RF, U.K.
}

\begin{abstract}
We investigated the ability of phenylephrine (PE), an $\alpha$-adrenergic agonist and promoter of hypertrophic growth in the ventricular myocyte, to activate the three best-characterized mitogen-activated protein kinase (MAPK) subfamilies, namely p38-MAPKs, SAPKs/JNKs (i.e. stress-activated protein kinases/c-Jun N-terminal kinases) and ERKs (extracellularly responsive kinases), in perfused contracting rat hearts. Perfusion of hearts with $100 \mu \mathrm{M}$ PE caused a rapid (maximal at $10 \mathrm{~min}$ ) 12fold activation of two p38-MAPK isoforms, as measured by subsequent phosphorylation of a p38-MAPK substrate, recombinant MAPK-activated protein kinase 2 (MAPKAPK2). This activation coincided with phosphorylation of p38-MAPK. Endogenous MAPKAPK2 was activated 4-5-fold in these perfusions and this was inhibited completely by the p38-MAPK inhibitor, SB203580 $(10 \mu \mathrm{M})$. Activation of p38-MAPK and MAPKAPK2 was also detected in non-contracting hearts per-
\end{abstract}

fused with PE, indicating that the effects were not dependent on the positive inotropic/chronotropic properties of the agonist. Although SAPKs/JNKs were also rapidly activated, the activation (2-3-fold) was less than that of p38-MAPK. The ERKs were activated by perfusion with $\mathrm{PE}$ and the activation was at least $50 \%$ of that seen with $1 \mu \mathrm{M}$ PMA, the most powerful activator of the ERKs yet identified in cardiac myocytes. These results indicate that, in addition to the ERKs, two MAPK subfamilies, whose activation is more usually associated with cellular stresses, are activated by the $\mathrm{G}_{\mathrm{q} / 11}$-protein-coupled receptor $\left(\mathrm{G}_{\mathrm{q} / 11} \mathrm{PCR}\right)$ agonist, $\mathrm{PE}$, in whole hearts. These data indicate that $G_{q / 11} P C R$ agonists activate multiple MAPK signalling pathways in the heart, all of which may contribute to the overall response (e.g. the development of the hypertrophic phenotype).

\section{INTRODUCTION}

The mitogen-activated protein kinases (MAPKs) are a large family of widely expressed protein Ser-/Thr-kinases (reviewed in [1-4]). Three subfamilies of the MAPKs have been clearly identified: the extracellularly responsive kinases (ERKs), the cJun N-terminal kinases (JNKs) which are also known as the stress-activated protein kinases (SAPKs), and the p38-MAPKs (also known as RK, Mxi-2, CSBP or HOG-1-related kinases). The ERKs are largely involved in cell growth, division and differentiation, whereas the SAPKs/JNKs and p38-MAPKs respond preferentially to cellular stresses. Numerous substrates for the MAPKs have been identified and many of these are intimately involved in cellular regulation. These include transcription factors and other protein kinases such as MAPKactivated protein kinase 2 (MAPKAPK2), a protein kinase which is phosphorylated and activated principally by $\mathrm{p} 38$ MAPKs and which is responsible for the phosphorylation of the small heat shock proteins HSP25/27 [5,6].

Members of all three subfamilies of MAPKs are present in the heart and are activated by a variety of agonists. The regulation of ERK activation has been studied in detail. $\mathrm{G}_{\mathrm{q}}$-protein-coupled receptor $\left(\mathrm{G}_{\mathrm{q}} \mathrm{PCR}\right)$ agonists such as endothelin-1 (ET-1) and $\alpha_{1}$ adrenergic agonists [e.g. phenylephrine (PE), noradrenaline] activate the ERKs in primary cultures of neonatal rat ventricular myocytes [7-11] and in freshly isolated myocytes from adult rat hearts [12]. This activation is probably mediated through the classical and/or novel isoforms of protein kinase $\mathrm{C}$, since it can be attenuated by depletion of these protein kinase $\mathrm{C}$ enzymes by chronic treatment with PMA $[8,10]$. Acute treatment of cultured myocytes or perfused hearts with PMA results in a powerful activation of the ERKs [7,8,12]. ET-1, PE and PMA are all hypertrophic in ventricular myocytes, implicating the ERKs in this response (reviewed in [13,14]). However, other work has suggested that activation of ERKs in cultured myocytes may be anti-apoptotic rather than hypertrophic [15].

The regulation of the activation of the 'stress-regulated' MAPKs (SAPKs/JNKs and p38-MAPKs) in the heart has been less extensively studied. The SAPKs/JNKs are activated in cultured myocytes by a variety of cellular stresses (hyperosmotic shock, metabolic stress or the protein synthesis inhibitor, anisomycin) [16]. They are moderately activated by ET-1 and PE, but are not activated by PMA [16,17]. In the perfused rat heart, SAPKs/JNKs are activated during reperfusion following global ischaemia [18-20], suggesting that they may play a role in cardiac pathology. The regulation of p38-MAPK has not been studied in myocytes in any detail, but, in perfused hearts, p38-MAPK and its substrate MAPKAPK 2 are activated by global ischaemia, and this is maintained or increased during reperfusion $[19,20]$. The biological function of the 'stress-regulated' MAPKs in the heart

Abbreviations used: DTT, dithiothreitol; ECL, enhanced chemiluminescence; ERK, extracellularly responsive kinase; ET, endothelin; GPCR, Gprotein-coupled receptor; GST, glutathione S-transferase; JNK, c-Jun N-terminal kinase; MAPK, mitogen-activated protein kinase; MAPKAPK2, MAPKactivated protein kinase 2; MBP, myelin basic protein; PE, phenylephrine; SAPK, stress-activated protein kinase. The term 'stress-regulated' MAPKs is used to denote generically the p38-MAPKs and the SAPKs/JNKs.

1 To whom correspondence should be addressed (e-mail p.sugden@ic.ac.uk). 
is unclear. Whereas evidence from work with other cells suggests that 'stress-regulated' MAPKs could be pro-apoptotic [21-25], transient transfection experiments have suggested that they may be hypertrophic in ventricular myocytes $[17,19,26]$. Most studies in the heart have used primary cultures of neonatal rat myocytes and there have been relatively few studies on the activation of MAPKs in perfused hearts. Here we have examined the regulation of all three MAPK subfamilies in this system by the hypertrophic $\alpha$-adrenergic agonist PE.

\section{EXPERIMENTAL}

\section{Materials}

Protein A-Sepharose and most other biochemicals used were obtained from Sigma (Poole, Dorset, U.K.). Prestained molecular-mass markers, biotinylated anti-rabbit IgG, enhanced chemiluminescence (ECL) Western blotting reagents and Hyperfilm MP were from Amersham International (Amersham, Bucks., U.K.). $\left[\gamma_{-}{ }^{32} \mathrm{P}\right] \mathrm{ATP}$ was from NEN Life Sciences (Brussels, Belgium). SDS/PAGE reagents and Bradford [27] protein assay reagent were from Bio-Rad (Hemel Hempstead, Herts., U.K.). Nitrocellulose from Schleicher and Schuell was supplied by Anderman and Co. (Kingston-upon-Thames, Surrey, U.K.). The MAPKAPK2 substrate peptide (KKLNRTLSVA [6,28]) was synthesized by Severn Biotech (Kidderminster, Worcs., U.K.). SB203580 was a gift from Dr. John C. Lee (SmithKline Beecham, King of Prussia, PA, U.S.A.) and a $10 \mathrm{mM}$ stock solution was prepared in DMSO. General laboratory chemicals were obtained from Merck (Lutterworth, Leics., U.K.).

The antibody to p38-MAPK (sc-535), raised to amino acids 341-360 at the C-terminus of the mouse sequence, was obtained from Santa Cruz Biotechnology Inc. (supplied by Autogen Bioclear, Devizes, Wilts., U.K.). The antibody to the dually phosphorylated form of p38-MAPK was from New England Biolabs (Hitchin, Herts., U.K.). The catalytic domain of murine MAPKAPK2 (amino acid residues 46-400) and the N-terminal transactivation domain of human c-Jun (amino acid residues 1-135) were expressed as glutathione S-transferase (GST) fusion proteins in Escherichia coli and were purified by GSH-Sepharose (Pharmacia, St. Albans, Herts., U.K.) chromatography [29]. The MAPKAPK2(46-400) region encompasses the following residues phosphorylatable by p38-MAPK: Thr-222, Thr-272 and Thr334 [30]. The c-Jun(1-135) region encompasses the following residues phosphorylatable by SAPKs/JNKs: Ser-63, Ser-73, Thr-91 and Thr-93 [31].

\section{Heart perfusions}

Adult male (250-300 g) Sprague-Dawley rat hearts were perfused retrogradely at a pressure of $10 \mathrm{kPa}(70 \mathrm{mmHg})$ with KrebsHenseleit bicarbonate-buffered saline $\left[25 \mathrm{mM} \mathrm{NaHCO}_{3} / 119 \mathrm{mM}\right.$ $\mathrm{NaCl} / 4.7 \mathrm{mM} \mathrm{KCl} / 2.5 \mathrm{mM} \mathrm{CaCl} / 1.2 \mathrm{mM} \mathrm{KH}_{2} \mathrm{PO}_{4}$ (pH 7.6 at $37^{\circ} \mathrm{C}$ )] supplemented with $10 \mathrm{mM}$ glucose and equilibrated with $95 \% \mathrm{O}_{2} / 5 \% \mathrm{CO}_{2}$. The temperature of the perfusates and hearts was maintained at $37^{\circ} \mathrm{C}$ by the use of a water-jacketed apparatus. All hearts were perfused for a 15 min equilibration period under these conditions. PE was added to the requisite concentration after the equilibration period and hearts were perfused for a further 2-45 min. Similarly, hearts were perfused with $1 \mu \mathrm{M}$ PMA for 5 min after the equilibration period. When the inhibitor SB203580 was used, it was added $10 \mathrm{~min}$ before the addition of $\mathrm{PE}$ and was present at a concentration of $10 \mu \mathrm{M}$ throughout the perfusion with PE. Control experiments (results not shown) established that the DMSO solvent alone did not affect any of the variables measured.
For hearts subjected to global ischaemia followed by reperfusion, the perfusion was interrupted for $20 \mathrm{~min}$ by clamping the aortic perfusion line. Hearts ceased beating within $1 \mathrm{~min}$ of ischaemia. The ischaemic hearts were then reperfused for $10 \mathrm{~min}$ by reopening the aortic perfusion line. Hearts resumed beating within $1 \mathrm{~min}$ of reperfusion and coronary flow returned to within $80 \%$ of control values (control: $13 \mathrm{ml} / \mathrm{min}$ per heart; reperfused: $11 \mathrm{ml} / \mathrm{min}$ per heart). Control hearts were perfused for up to $45 \mathrm{~min}$ after the pre-equilibration period without interruption of the perfusate flow. To arrest the hearts, the concentration of $\mathrm{KCl}$ in the perfusion medium was increased to $40 \mathrm{mM}$. At the end of the perfusions, hearts were 'freeze-clamped' between aluminium tongs cooled in liquid nitrogen, pulverized under liquid nitrogen and the powders were stored at $-80^{\circ} \mathrm{C}$.

\section{In-gel kinase assays}

MAPKs in whole-heart extracts were assayed by the in-gel kinase method [32]. Heart powders were homogenized with $3 \mathrm{ml} / \mathrm{g}$ of buffer A [20 mM $\beta$-glycerophosphate, $\mathrm{pH} 7.5 / 50 \mathrm{mM}$ $\mathrm{NaF} / 2 \mathrm{mM}$ EDTA/0.2 mM $\mathrm{Na}_{3} \mathrm{VO}_{4} / 5 \mathrm{mM}$ dithiothreitol (DTT) $/ 10 \mathrm{mM}$ benzamidine $/ 200 \mu \mathrm{M}$ leupeptin $/ 120 \mu \mathrm{M}$ pepstatin $\mathrm{A} / 10 \mu \mathrm{M}$ trans-epoxy succinyl-L-leucylamido-(4-guanidino)butane $/ 300 \mu \mathrm{M}$ PMSF $/ 1 \%$ (v/v) Triton X-100] and extracted on ice $(5 \mathrm{~min})$. The samples were centrifuged $(10000 \mathrm{~g}$, 5 min, $4^{\circ} \mathrm{C}$ ) and the supernatants were boiled with 0.33 vol. of SDS/PAGE sample buffer [0.33 M Tris/ $\mathrm{HCl}$, pH $6.8 / 10 \%$ (w/v) SDS $/ 13 \% \quad(\mathrm{v} / \mathrm{v})$ glycerol $/ 133 \mathrm{mM} \quad$ DTT $/ 0.2 \mathrm{mg} / \mathrm{ml}$ Bromophenol Blue]. Protein concentrations were determined using the Bradford method [27]. Proteins (100 $\mu \mathrm{g}$ loaded/lane) were separated on $10 \%(\mathrm{w} / \mathrm{v}) \mathrm{SDS} /$ polyacrylamide gels with a $6 \%(\mathrm{w} / \mathrm{v})$ stacking gel. The $10 \%$ gels were formed in the presence of $0.5 \mathrm{mg} / \mathrm{ml}$ GST-MAPKAPK2(46-400) for the assay of p38-MAPKs, $0.5 \mathrm{mg} / \mathrm{ml} \mathrm{GST-c-Jun(1-135)} \mathrm{for} \mathrm{the} \mathrm{assay} \mathrm{of}$ SAPKs/JNKs, or $0.5 \mathrm{mg} / \mathrm{ml}$ myelin basic protein (MBP) for the assay of ERKs. After electrophoresis, SDS was removed from the gels by washing in $20 \%(\mathrm{v} / \mathrm{v})$ propan-2-ol in $50 \mathrm{mM}$ Tris $/ \mathrm{HCl}, \mathrm{pH} 8.0(3 \times 20 \mathrm{~min})$. The propan-2-ol was removed by washing in $50 \mathrm{mM}$ Tris $/ \mathrm{HCl}, \mathrm{pH} 8.0 / 5 \mathrm{mM}$ 2-mercaptoethanol $(3 \times 20 \mathrm{~min})$. Proteins were denatured in $6 \mathrm{M}$ guanidine/ $\mathrm{HCl} / 50 \mathrm{mM}$ Tris/HCl, $\mathrm{pH} 8.0 / 5 \mathrm{mM}$ 2-mercaptoethanol $(2 \times$ $30 \mathrm{~min}$ ), then renatured in $50 \mathrm{mM}$ Tris $/ \mathrm{HCl}, \mathrm{pH} 8.0 / 5 \mathrm{mM} 2-$ mercaptoethanol/0.04\% (v/v) Tween $40(1 \times 30 \mathrm{~min}, 2 \times 1 \mathrm{~h}$, $\left.1 \times 18 \mathrm{~h}, 1 \times 30 \mathrm{~min}, 4^{\circ} \mathrm{C}\right)$. The gels were equilibrated to room temperature with $40 \mathrm{mM}$ Hepes $\mathrm{pH} 8.0 / 2 \mathrm{mM}$ DTT/10 mM $\mathrm{MgCl}_{2}(2 \times 30 \mathrm{~min})$ and incubated for $3 \mathrm{~h}$ with $12.5 \mu \mathrm{Ci} / \mathrm{gel}$ of $\left[\gamma-{ }^{32} \mathrm{P}\right] \mathrm{ATP}$ in $5 \mathrm{ml}$ of $40 \mathrm{mM}$ Hepes, $\mathrm{pH} 8.0 / 0.5 \mathrm{mM}$ EGTA/ $10 \mathrm{mM} \mathrm{MgCl}_{2} / 50 \mu \mathrm{M} \mathrm{ATP} / 0.1 \mu \mathrm{M}$ cAMP-dependent protein kinase inhibitor. The reaction was stopped and gels were washed with $1 \%(\mathrm{w} / \mathrm{v})$ disodium pyrophosphate $/ 5 \%(\mathrm{w} / \mathrm{v})$ trichloroacetic acid. The gels were dried on to $3 \mathrm{MM}$ Whatman chromatography paper and autoradiographed. In-gel kinase activities were quantified by laser scanning densitometry.

\section{Immunoprecipitation}

Heart powders were homogenized with $3 \mathrm{ml} / \mathrm{g}$ immunoprecipitation buffer $[10 \mathrm{mM}$ Tris $/ \mathrm{HCl}, \mathrm{pH} 7.4 / 5 \mathrm{mM}$ EDTA/ $50 \mathrm{mM} \mathrm{NaF} / 50 \mathrm{mM} \mathrm{NaCl} / 0.3 \mathrm{mM} \mathrm{Na}_{3} \mathrm{VO}_{4} / 0.1 \%$ (w/v) fatty acid-free BSA $/ 20 \mu \mathrm{g} / \mathrm{ml}$ aprotinin] containing $20 \mathrm{mM}$-octyl $\beta$ D-glucopyranoside and $1 \%(\mathrm{v} / \mathrm{v})$ Triton X-100. The samples were extracted on ice $(10 \mathrm{~min})$ and centrifuged $(10000 \mathrm{~g}, 5 \mathrm{~min}$, $\left.4{ }^{\circ} \mathrm{C}\right)$. The supernatants $(150 \mu \mathrm{l})$ were incubated with $8 \mu \mathrm{l}(0.8 \mu \mathrm{g})$ of p38-MAPK antibody on a rotating wheel $\left(2 \mathrm{~h}, 4^{\circ} \mathrm{C}\right)$. Protein A-Sepharose was added $(20 \mu 1$ of a $50 \%$ slurry in immuno- 
precipitation buffer) and the samples were rotated for a further $1 \mathrm{~h}$. The samples were centrifuged $\left(10000 \mathrm{~g}, 1 \mathrm{~min}, 4^{\circ} \mathrm{C}\right)$ and the supernatant was removed and boiled with 0.33 vol. of SDS/ PAGE sample buffer. The pellet was washed in immunoprecipitation buffer $\left(3 \times 150 \mu 1,4^{\circ} \mathrm{C}\right)$, resuspended in $150 \mu \mathrm{l}$ and boiled with $50 \mu 1$ of SDS/PAGE sample buffer. Samples $(30 \mu 1)$ were assayed for p38-MAPK activity by the in-gel kinase method.

\section{Western blot analysis}

Western blots for phospho-p38-MAPK were performed according to the manufacturer's instructions. The bands were detected using ECL with exposure to Hyperfilm MP. Blots were quantified by laser scanning densitometry.

\section{FPLC of ERKs and MAPKAPK2}

Supernatants of heart powders were homogenized with $12 \mathrm{ml} / \mathrm{g}$ of buffer $\mathrm{A}$ and centrifuged $\left(10000 \mathrm{~g}, 2 \times 5 \mathrm{~min}, 4^{\circ} \mathrm{C}\right)$. Proteins in samples $(0.5 \mathrm{ml})$ were separated by FPLC. ERKs were separated on a Mono Q HR5/5 column equilibrated with $50 \mathrm{mM}$ Tris/HCl, $\mathrm{pH} 7.3 / 2 \mathrm{mM}$ EDTA/2 mM EGTA/0.1\% (v/v) 2mercaptoethanol $/ 5 \%$ (v/v) glycerol $/ 0.03 \%$ (v/v) Brij-35/ $0.3 \mathrm{mM} \mathrm{Na} \mathrm{VO}_{4} / 1 \mathrm{mM}$ benzamidine $/ 4 \mu \mathrm{g} / \mathrm{ml}$ leupeptin. After a $5 \mathrm{ml}$ isocratic wash, ERKs were separated using a linear $\mathrm{NaCl}$ gradient $(20 \mathrm{ml}, 0-0.33 \mathrm{M} \mathrm{NaCl})$ at a flow rate of $1 \mathrm{ml} / \mathrm{min}$ with collection of $0.5 \mathrm{ml}$ fractions. They were assayed by the incorporation of ${ }^{32} \mathrm{P}$ from $\left[\gamma^{32} \mathrm{P}\right] \mathrm{ATP}$ into MBP by the 'direct' method as previously described [7]. Samples of fractions were also taken for in-gel kinase assays and were boiled with 0.33 vol. of SDS/PAGE sample buffer.

For MAPKAPK2, heart extracts were applied to a Mono S HR5/5 column equilibrated with $25 \mathrm{mM} \beta$-glycerophosphate, $\mathrm{pH} 7.3 / 2 \mathrm{mM}$ EDTA/0.5 mM DTT $/ 5 \%$ (v/v) glycerol $/ 0.1 \%$ (v/v) Triton X-100/50 $\mu \mathrm{g} / \mathrm{ml}$ PMSF. After a $5 \mathrm{ml}$ isocratic wash, MAPKAPK2 was eluted using a linear $\mathrm{NaCl}$ gradient $(15 \mathrm{ml}$, $0-0.3 \mathrm{M} \mathrm{NaCl}$ ) at a flow rate of $1 \mathrm{ml} / \mathrm{min}$ with collection of $1 \mathrm{ml}$ fractions. MAPKAPK2 was assayed by the incorporation of ${ }^{32} \mathrm{P}$ from $\left[\gamma-{ }^{32} \mathrm{P}\right]$ ATP into KKLNRTLSVA peptide substrate $[6,28]$ as previously described [19], except that the incubation time was decreased to $10 \mathrm{~min}$. To determine total MAPKAPK2 activity, areas under peaks of activity were integrated and corrected for variation in the amounts of protein applied to the column.

\section{Expression of results}

Results are expressed as means \pm S.E.M. when three or more independent observations were made or as means \pm range when two independent observations were made.

\section{RESULTS}

\section{Activation of p38-MAPKs by PE}

Activation of p38-MAPKs was studied in extracts from hearts perfused under control conditions or with $100 \mu \mathrm{M}$ PE, using ingel kinase assays with GST-MAPKAPK2(46-400) as substrate. This concentration of $\mathrm{PE}$ has been used extensively for induction of hypertrophy in ventricular myocytes [33,34]. Hearts that had been subjected to ischaemia/reperfusion, which strongly activates p38-MAPKs [19], were used as a positive control. PE stimulated a large increase in p38-MAPK activation (approximately 12-fold relative to controls) (Figures $1 \mathrm{~A}$ and 1B). This activation was comparable with that obtained after ischaemia/reperfusion. Maximal activation was observed from 5 min and p38-MAPK activity remained elevated over $45 \mathrm{~min}$ (approximately 6-fold relative to controls) (Figures 1A and 1B). An antibody to p38-
A

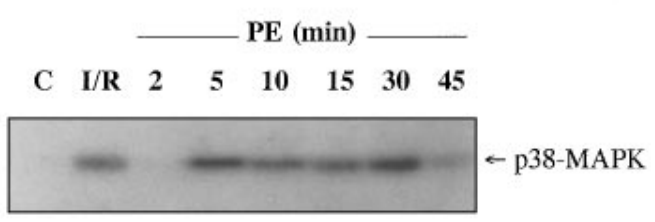

B

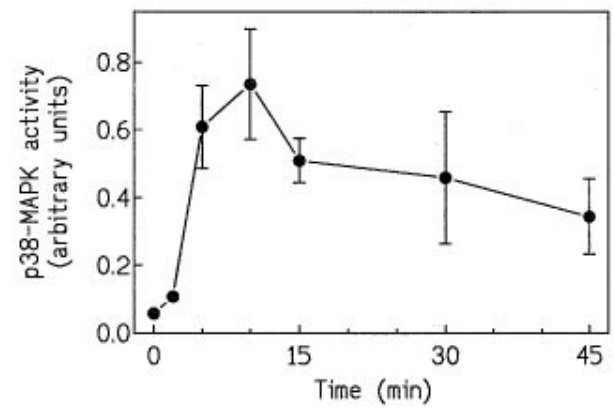

C

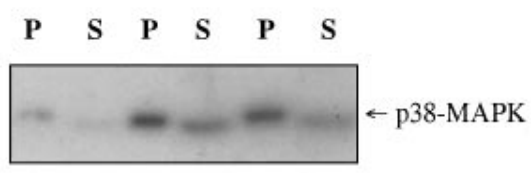

$\begin{array}{llll}\text { PE (min) } & 0 & 15 & 30\end{array}$

Figure 1 Activation of p38-MAPK in hearts exposed to PE or ischaemia/ reperfusion

Hearts were perfused under control conditions (C), subjected to ischaemia (20 min) and reperfusion (10 min) (I/R), or perfused with $100 \mu \mathrm{M}$ PE for the times indicated, as described in the Experimental section. (A) p38-MAPK activities in whole extracts were determined by ingel kinase assays with GST-MAPKAPK2(46-400) as substrate. (B) Autoradiograms were quantified by laser scanning densitometry. Each point represents the mean \pm range of two

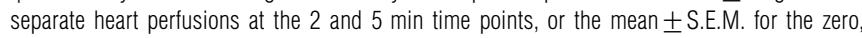
10, 15, 30 and 45 min time points (three or four separate heart perfusions at each time point). (C) p38-MAPK activities were measured by in-gel kinase assays in immunoprecipitates of extracts $(\mathrm{P})$ or residual supernatants $(\mathrm{S})$ of hearts perfused with $100 \mu \mathrm{M}$ PE for the times indicated. The experiment was repeated on two further occasions with similar results.

MAPK immunoprecipitated approx. $60 \%$ of the total activity detected with in-gel assays (Figure 1C). The proportion of p38MAPK activity immunoprecipitated was not affected by doubling the amount of antibody added. The apparent molecular mass of the immunoprecipitated p38-MAPK activity was slightly greater than that remaining in the supernatant, suggesting that more than one isoform of p38-MAPK may be activated in the perfused heart. We have attempted to detect p38-MAPK $\beta$ and p38MAPK $\gamma$ by Western blotting using antibodies from Santa Cruz Biotechnology Inc., but have so far been unable to detect either of these isoforms (A. Clerk and P. H. Sugden, unpublished work). p38-MAPK is activated by dual phosphorylation of a Thr and a Tyr residue within a Thr-Gly-Tyr sequence [35]. Phosphorylation of p38-MAPK in hearts perfused with PE was confirmed by immunoblotting using an antibody which recognizes the dually phosphorylated $\operatorname{Thr}(P)$-Gly-Tyr $(P)$ sequence of the p38-MAPKs. As with the in-gel kinase assays, phosphorylated p38-MAPK was detected from 5 min perfusion with PE and was elevated over 45 min (Figure 2). The extent of p38MAPK phosphorylation was similar to that in hearts subjected to ischaemia/reperfusion. 


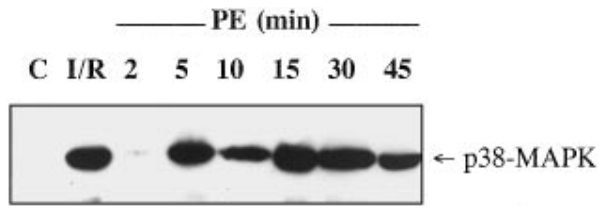

Figure 2 Stimulation of p38-MAPK phosphorylation by PE

Hearts were perfused under control conditions (C), subjected to ischaemia $(20 \mathrm{~min})$ and reperfusion $(10 \mathrm{~min})(\mathrm{I} / \mathrm{R})$, or perfused with $100 \mu \mathrm{M} \mathrm{PE}$ for the times indicated, as described in the Experimental section. Extracts were subjected to SDS/PAGE and immunoblotted with an antibody against phospho-p38-MAPK. The experiment was repeated with similar results.
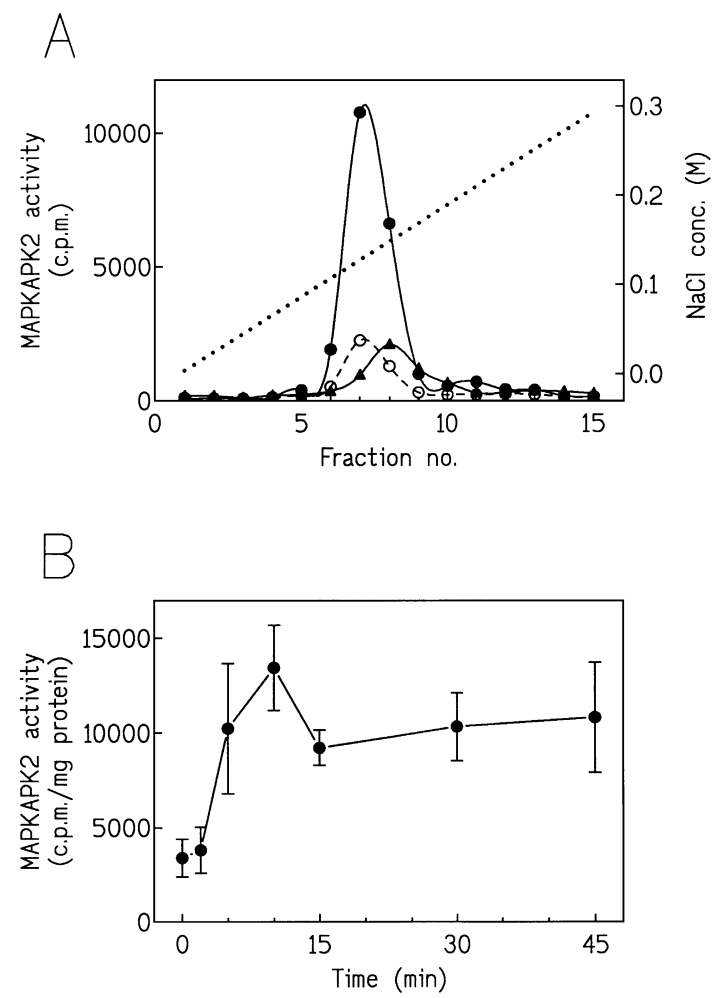

Figure 3 Activation of MAPKAPK2 in hearts perfused with PE

Hearts were perfused with $100 \mu \mathrm{M} \mathrm{PE}$, and MAPKAPK2 was purified by Mono S FPLC and assayed as described in the Experimental section. (A) A typical elution profile of MAPKAPK2 activity in hearts perfused under control conditions ( $\mathrm{O}$, broken line), or with $100 \mu \mathrm{M} \mathrm{PE}$ for $2 \mathrm{~min}$ ( $\mathbf{\Delta}$, solid line) or $30 \mathrm{~min}$ (- solid line). The NaCl gradient is shown by the dotted line. (B) MAPKAPK2 activities from hearts perfused with $100 \mu \mathrm{M}$ PE were obtained by integration of the areas under the Mono S FPLC peaks expressed relative to protein loaded. Each point represents the mean \pm range of two separate heart perfusions at the 2 and 5 min time points, or the mean \pm S.E.M. for the zero, $10,15,30$ and 45 min time points (three or four separate heart perfusions at each time point).

\section{Activation of MAPKAPK2 in hearts perfused with PE}

MAPKAPK2 is selectively phosphorylated and activated by p38-MAPK [6] and is thus a useful index of p38-MAPK activation. MAPKAPK2 activity was assayed in extracts from hearts perfused with $100 \mu \mathrm{M}$ PE, after its partial purification by Mono S FPLC. As in our previous studies [19], MAPKAPK2 eluted as a single peak of activity at approximately $0.15 \mathrm{M} \mathrm{NaCl}$ (Figure 3A). No activity was detectable after 2 min perfusion to PE (Figures 3A and 3B), but MAPKAPK2 was clearly activated at $5 \mathrm{~min}$ (Figure 3B). As with p38-MAPK, maximal

\section{Table 1 Effect of SB203580 on the activation of MAPKAPK2 by PE}

Hearts were perfused for $10 \mathrm{~min}$ as described in the Experimental section. MAPKAPK2 activities were measured after partial purification by FPLC and are the means \pm S.E.M. of 3-4 separate heart perfusions. Statistical significance by a two-tailed $t$-test: ${ }^{\star} P<0.02$.

Perfusion condition

MAPKAPK2 activity (c.p.m/mg of protein)

$\begin{array}{lc}\text { Control } & 2995 \pm 714 \\ \text { PE }(100 \mu \mathrm{M}) & 10823 \pm 1980^{\star} \\ \text { PE }(100 \mu \mathrm{M})+\text { SB203580 }(10 \mu \mathrm{M}) & 1109 \pm 97\end{array}$

A

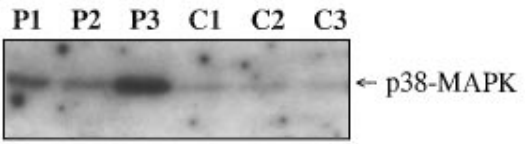

B

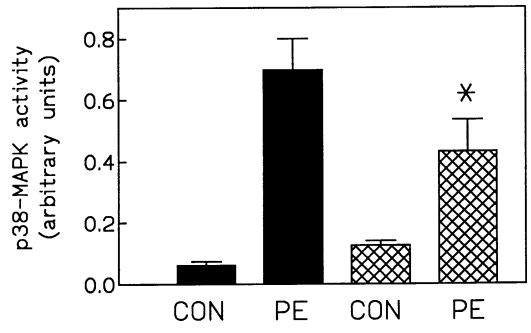

Figure 4 Activation of p38-MAPK in arrested hearts perfused with PE

Hearts were arrested with $40 \mathrm{mM} \mathrm{KCl}$ and perfused with $100 \mu \mathrm{M}$ PE for $10 \mathrm{~min}$. (A) p38-MAPK activities in whole extracts of three individual hearts perfused under control (arrested) conditions (C1, C2, C3) or of three individual hearts perfused with PE (P1, P2, P3) were determined by in-gel kinase assays with GST-MAPKAPK2(46-400) as substrate. (B) Autoradiograms were quantified by laser scanning densitometry. For arrested hearts (cross-hatched bars), results are means \pm S.E.M. of five separate heart perfusions. Statistical significance by a two-tailed $t$-test: ${ }^{*} P<0.01$ compared with control (CON) perfusions. For comparison, activation of p38-MAPK in contracting hearts perfused for 10 min with $100 \mu \mathrm{M}$ PE is also shown (solid bars, mean \pm S.E.M., three separate heart perfusions).

activation was observed from 5 to $10 \mathrm{~min}$ (approximately 4-fold relative to controls) and this was sustained over $45 \mathrm{~min}$ (Figure $3 \mathrm{~B}$ ). The degree of activation of MAPKAPK2 was comparable to that observed in ischaemic/reperfused hearts (results not shown). SB203580, the selective p38-MAPK inhibitor [36,37], abolished the activation of MAPKAPK2 by PE (Table 1), demonstrating that p38-MAPK was indeed responsible for activation of MAPKAPK2.

\section{Activation of p38-MAPK and MAPKAPK2 in arrested hearts}

$\alpha_{1}$-Adrenergic agonists such as PE increase the contractility of the heart (reviewed in [38]). To confirm that activation of p38MAPK and MAPKAPK2 by PE in perfused hearts was a direct result of $\alpha_{1}$-adrenergic receptor stimulation and was independent of its effects on contractility, the activities of these kinases were assessed in PE-perfused hearts arrested with a high concentration of $\mathrm{KCl}(40 \mathrm{mM})$. p38-MAPK was activated in arrested hearts perfused with PE for $10 \mathrm{~min}$ (Figures $4 \mathrm{~A}$ and 4B). Although 
A

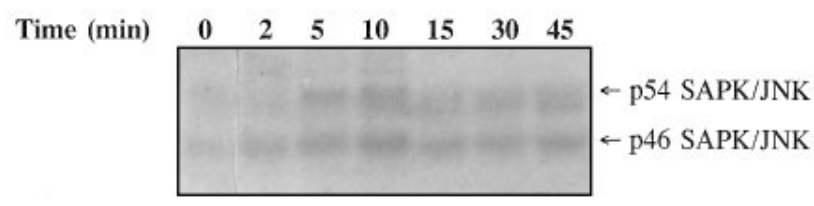

B

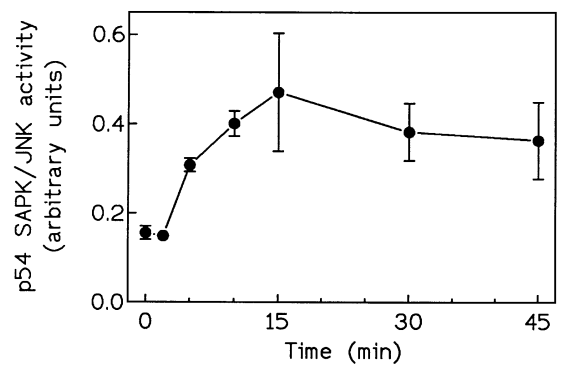

C

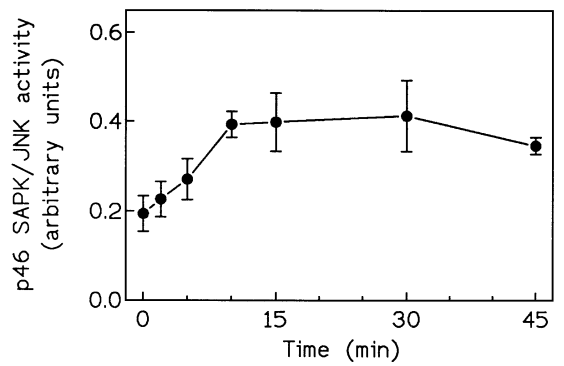

Figure 5 Activation of SAPKs/JNKs in hearts perfused with PE

Hearts were perfused with $100 \mu \mathrm{MPE}$ for the times indicated, as described in the Experimental section. (A) SAPK/JNK activities in whole extracts were determined by in-gel kinase assays with GST-C-Jun(1-135) as substrate. The autoradiogram presented was obtained from a single gel. Autoradiograms were quantified by laser scanning densitometry for $(\mathbf{B})$ the $54 \mathrm{kDa}$ or $(\mathbf{C})$ the $46 \mathrm{kDa}$ SAPK/JNK activities. Each point represents the mean + range of two separate heart perfusions at the 2 and 5 min time points, or the mean \pm S.E.M. for the zero, 10, 15, 30 and $45 \mathrm{~min}$ time points (three or four separate heart perfusions at each time point).

activation by PE was attenuated in arrested hearts relative to the contracting hearts, this was not significant (Figure 4B). For each perfusion condition, MAPKAPK2 activity was assayed in two of the hearts. Although arrest may have diminished MAPKAPK2 activation by PE, it was still clearly detectable [arrested hearts: PE (10 min), 7572 and 7129 c.p.m./mg of protein; controls, 3917 and 3262 c.p.m./mg of protein; non-arrested hearts: PE (10 min), 15686 and 11185 c.p.m./mg of protein; controls, 3945 and 2343 c.p.m./mg of protein].

\section{Activation of SAPKs/JNKs by PE}

PE stimulates a modest (approx. 2-fold) activation of SAPKs/ JNKs in cultured ventricular myocytes $[16,17]$. We therefore examined the effects of PE on SAPK/JNK activity in hearts perfused with $100 \mu \mathrm{M}$ PE (Figures 5A-5C). p46 and p54 SAPKs/ JNKs were activated in hearts perfused with PE from 5 min and remained elevated after perfusion for $45 \mathrm{~min}$, with maximal activation (approx. 2- to 3-fold relative to controls) of both being observed at 10-15 min. On occasion, the $54 \mathrm{kDa}$ SAPK/JNK activity can be resolved into two bands of approx. 52 and $54 \mathrm{kDa}$ (see the $10 \mathrm{~min}$ time point in Figure 5A). We have separated these activities by Mono Q FPLC (A. Clerk and P. H. Sugden,
A
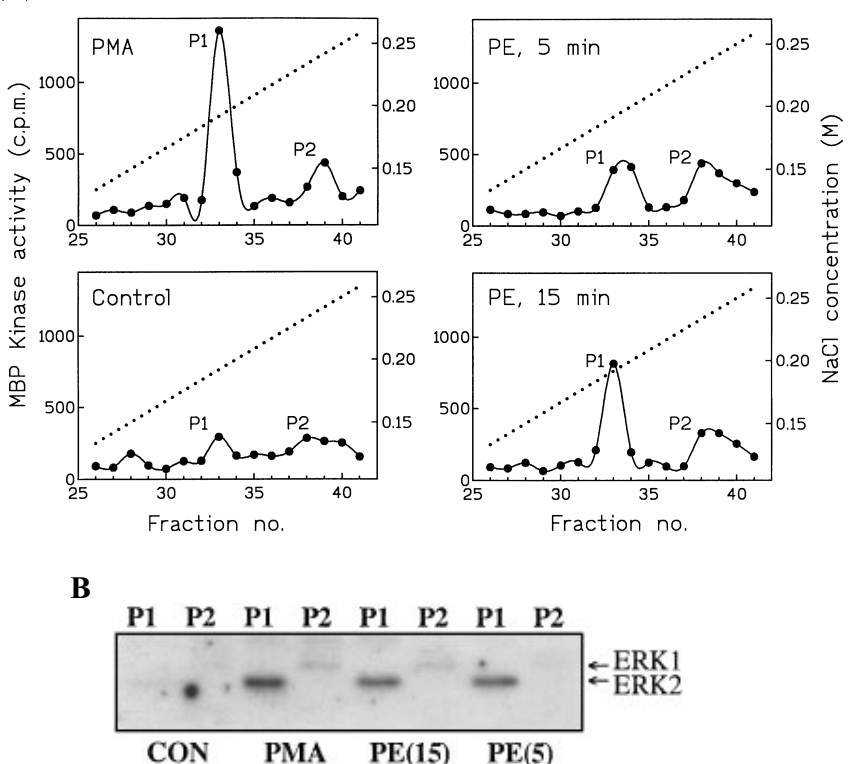

Figure 6 Activation of ERKs in hearts exposed to PE or PMA

Hearts were perfused with $100 \mu \mathrm{M}$ PE for 5 or 15 min, or with $1 \mu \mathrm{M}$ PMA for 5 min as described in the Experimental section. (A) ERKs were purified by Mono Q FPLC and assayed as described in the Experimental section. The $\mathrm{NaCl}$ gradients are shown by the dotted lines. (B) ERK activities in the peak fractions (labelled P1 and P2) were assayed by the in-gel kinase method with MBP as substrate.

unpublished work). The $52 \mathrm{kDa}$ SAPK/JNK activity elutes at $0.08 \mathrm{M} \mathrm{NaCl}$, whereas the $54 \mathrm{kDa}$ SAPK/JNK activity elutes at $0.15 \mathrm{M} \mathrm{NaCl}$. We have not yet identified which isoforms of SAPKs/JNKs these represent.

\section{Activation of ERKs by PE}

Our previous studies using in-gel kinase assays demonstrated that ERKs are activated by $\alpha$-adrenergic stimulation in perfused adult rat hearts [12]. These studies were completed before the 'stress-regulated' MAPKs were identified. Because p38-MAPK, ERK $1 / 2$ and p46-SAPK/JNK migrate close to one another on SDS/PAGE, and all phosphorylate MBP to a degree, we reexamined whether ERKs were activated by PE using partial purification by Mono Q FPLC. FPLC represents one of the best methods for establishing activation of ERKs. Consistent with our earlier studies [12], two peaks of activity eluted at approximately $0.20 \mathrm{M}$ and $0.24 \mathrm{M} \mathrm{NaCl}$ (Figure 6A). As shown by in-gel kinase assays with MBP as substrate, these correspond to $42 \mathrm{kDa}$ ERK2 and $44 \mathrm{kDa}$ ERK1 respectively (Figure 6B). ERK1 and ERK2 activities were detected after 5 min perfusion with $100 \mu \mathrm{M}$ PE, consistent with our previous study [12]. This activity was further increased in hearts perfused with PE for $15 \mathrm{~min}$ and was at least $50 \%$ of that obtained in hearts perfused with $1 \mu \mathrm{M}$ PMA for 5 min (Figures 6A and 6B). PMA is the most powerful activator of ERKs in cardiac myocytes yet identified $[8,10]$. These experiments clearly establish that ERKs are activated by $P E$.

\section{DISCUSSION}

Activation of the SAPKs/JNKs and p38-MAPKs by cellular stresses has been intensively investigated in numerous cell types (reviewed in [2,3]). There is also very limited evidence that these 
'stress-regulated' MAPKs may also be activated by GPCR agonists. p38-MAPK is activated in platelets by thrombin [39] and in neutrophils by the chemotactic peptide fMet-Leu-Phe [40,41]. Angiotensin II activates SAPKs/JNKs in rat liver epithelial cells [42] and Chinese hamster ovary fibroblasts overexpressing angiotensin II subtype 1a receptors [43]. ET-1 activates the SAPKs/JNKs in neonatal ventricular myocytes [16] and airway smooth muscle cells [44]. PE also activates SAPKs/JNKs in neonatal ventricular myocytes $[16,17]$. Although the cytoplasmic tail of the $\mathrm{ET}_{\mathrm{B}}$ receptor is capable of activating all three best-characterized MAPK (ERK, SAPK/JNK, p38-MAPK) cascades [45], activation of these MAPK subfamilies by agonist stimulation of the $\mathrm{ET}_{\mathrm{B}}$ receptor (or any other GPCR) has yet to be demonstrated. In this study, we have demonstrated that PE, a potent hypertrophic agent, activates the three MAPK subfamilies in perfused rat hearts. The mechanism of activation of 'stress-regulated' MAPKs by GPCR agonists is not understood. ET-1, PE and PMA activate protein kinase $\mathrm{C}$ in ventricular myocytes [9,46-48] and this probably accounts for much of the activation of ERKs by these agonists [8]. PMA does not activate the 'stress-regulated' MAPKs in these cells [16], suggesting that the activation of SAPKs/JNKs is not mediated by the classical or novel protein kinase $\mathrm{C}$ isoforms. The mechanism of activation of p38-MAPK by GPCRs is equally unclear.

p38-MAPK and MAPKAPK2 are strongly activated by ischaemia and/or reperfusion in perfused hearts [19,20]. PE also induced a rapid $(<5 \mathrm{~min})$ and sustained $(>45 \mathrm{~min})$ activation of p38-MAPKs (Figure 1) and the downstream substrate, MAPKAPK2 (Figure 3). Activation of these kinases was comparable with that seen in hearts subjected to ischaemia/ reperfusion (results not shown). An antibody to p38-MAPK $(\alpha)$ immunoprecipitated only approx. $60 \%$ of the total activity (Figure 1C). The activity remaining in the supernatant had a slightly lower apparent relative molecular mass, suggesting that at least two isoforms of p38-MAPK are activated by PE in the heart. These results are similar to those we have obtained with p38-MAPKs in hearts subjected to ischaemia and/or reperfusion or perfused with hydrogen peroxide [49]. All of this p38-MAPK activity is inhibited by $10 \mu \mathrm{M}$ SB203580 included in the $[\gamma$ ${ }^{32}$ P]ATP phosphorylation stage of in-gel assays with MAPKAPK2 as substrate [49]. Consistent with other studies [37], MAPKAPK2 activation by PE was completely inhibited by SB203580 (Table 1), indicating its dependence on activation of SB203580-sensitive p38-MAPKs. At least six isoforms of p38MAPK have been described [36,50-56]. p38-MAPK $(\alpha)$ and p38-MAPK $\beta$ each exist as two alternatively spliced isoforms $[36,55]$ and are inhibited by SB203580. p38-MAPK $\gamma$ and p38MAPK $\delta$ are resistant to inhibition by SB203580 [52,53,55]. Whereas we have evidence that SB203580 partially inhibits some isoforms of SAPKs/JNKs activated in perfused heart (A. Clerk and P. H. Sugden, unpublished work), these kinases do not phosphorylate MAPKAPK2 in in-gel kinase assays and there is currently no evidence to suggest that SAPKs/JNKs phosphorylate MAPKAPK2. We have also shown that $10 \mu \mathrm{M}$ SB203580 does not inhibit partially purified ERK1 or ERK2 activity (A. Clerk and P. H. Sugden, unpublished work). Our results are therefore consistent with the activation of at least two isoforms of $\mathrm{p} 38-\mathrm{MAPK}(\alpha)$ and/or $\mathrm{p} 38-\mathrm{MAPK} \beta$ in the heart, which are responsible for the activation of MAPKAPK2.

The biological role(s) of p38-MAPK(s) in ventricular myocytes is not understood. In other cell types, MAPKAPK2 phosphorylates the small heat shock proteins [5,6] and this may increase their cytoprotective ability [57]. It is not known whether this occurs in heart. p38-MAPK has been implicated in myocyte hypertrophy because transfection with constitutively activated
MKK6, to activate p38-MAPKs selectively, induces a full hypertrophic response [26]. SB203580 $(20 \mu \mathrm{M})$ inhibits the hypertrophy induced by MKK6 or by PE [26]. Since, particularly with respect to transfection of constitutively activated kinases, there is the possibility of 'cross-talk' from MKK6 to other MAPKs and high concentrations of SB203580 can inhibit certain isoforms of SAPK/JNK ([58]; A. Clerk and P. H. Sugden, unpublished work), these results are not definitive. In the study by Zechner et al. [26], PE-stimulated phosphorylation of p38MAPKs was examined. Our results show that the p38-MAPKs are indeed activated by $\mathrm{PE}$ and thus they may potentially contribute to the hypertrophic response.

Consistent with studies in cultured ventricular myocytes [16, 17], PE stimulated SAPK/JNK activity in perfused hearts. The modest activation of SAPKs/JNKs in perfused hearts (2-3-fold) is comparable with that observed in myocytes (approx. 2-fold $[16,17])$. The time course of activation in perfused hearts was similar to that of $\mathrm{p} 38$-MAPKs, indicating that the two 'stressregulated' MAPK cascades are activated in parallel by PE. Transfection of ventricular myocytes with constitutively activated MEKK1 and/or SEK1 to activate the SAPKs/JNKs selectively, stimulates transcriptional changes associated with hypertrophy and increases myocyte profile [17,19]. However, MEKK1 was first identified as an upstream activator of ERKs [59] and subsequently was shown to activate SAPKs/JNKs (reviewed in [60]). Furthermore, the SAPK/JNK kinase SEK1 (also known as MKK4 or JNKK1) can phosphorylate and activate p38MAPKs [61,62]. It is therefore not possible to identify a specific role for individual MAPKs in the hypertrophic response using these kinases.

$\alpha_{1}$-Adrenergic agonists are positively inotropic and chronotropic in the rat heart (reviewed in [38]). In neonatal ventricular myocytes in primary culture, passive stretch activates the SAPKs/JNKs [63]. Furthermore, the increased $\mathrm{O}_{2}$ consumption necessitated by the PE-induced increases in contractility might have rendered the heart ischaemic and this could have activated the p38-MAPKs in our experiments [19]. In order to prevent contraction, hearts were perfused with $40 \mathrm{mM} \mathrm{KCl}$. The effects of PE on the 'stress-regulated' MAPKs were examined in these arrested hearts. PE still activated p38-MAPK significantly in the arrested hearts relative to arrested controls (Figures 4A and 4B). As expected, activation of MAPKAPK2 by PE in arrested hearts reflected the p38-MAPK activity (see Results section for details). We also examined the activation of SAPKs/JNKs by PE in the arrested hearts (results not shown). However, the SAPKs/JNKs were elevated in hearts perfused with $40 \mathrm{mM} \mathrm{KCl}$ alone and, since the stimulation of SAPKs/JNKs by PE in contracting hearts was only 2-3-fold (Figure 5), it was not possible to determine whether there was significant activation of SAPKs/ JNKs by PE in arrested hearts.

Our previous studies using in-gel kinase assays have shown that ERKs are stimulated in hearts perfused with catecholamines (noradrenaline, a mixed $\alpha / \beta$ adrenergic agonist, and isoprenaline, a $\beta$ agonist) for $5 \min [12]$. However, these studies were completed before the 'stress-regulated' MAPKs had been identified. Since we detected strong activation of the 'stress-regulated' MAPKs by PE here, it was possible that these MAPKs could have been responsible for the in-gel MBP kinase activities originally attributed to the ERKs. We therefore re-examined the activation of ERKs by PE in perfused hearts after partial purification using Mono Q FPLC. This method allows the separation of the ERKs (eluted at $0.20 \mathrm{M}$ and $0.24 \mathrm{M} \mathrm{NaCl}$ ) from SAPKs/JNKs and p38-MAPK. The SAPKs/JNKs elute in the isocratic wash (a $44 \mathrm{kDa}$ isoform), $0.08 \mathrm{M} \mathrm{NaCl}$ (a $46 \mathrm{kDa}$ isoform with a minor $52 \mathrm{kDa}$ isoform) and $0.15 \mathrm{M} \mathrm{NaCl}$ (a $54 \mathrm{kDa}$ isoform) ([16]; A. 
Clerk and P. H. Sugden, unpublished work). p38-MAPK elutes at approximately $0.4 \mathrm{M} \mathrm{NaCl}$ ([6]; A. Clerk and P. H. Sugden, unpublished work). Here, we have confirmed that the ERKs are activated by PE in perfused hearts (Figure 6). ERK activation was detected at $5 \mathrm{~min}$, but was increased at $15 \mathrm{~min}$. This is in contrast with the situation in cultured neonatal ventricular myocytes, where ERK activation by PE is maximal at approx. $5 \min [9]$.

In conclusion, we have shown activation of $\mathrm{p} 38$-MAPKs and SAPKs/JNKs by the GPCR agonist, PE, in perfused hearts. There have been few reports of activation of these MAPKs by GPCR agonists and any such studies have normally focused on a single 'stress-regulated' MAPK subfamily. Here we show that, in a physiological setting (the perfused heart), a single GPCR agonist can activate all three MAPK subfamilies. The pathophysiological roles of the different MAPKs in such a situation remain to be established.

This work was supported by grants from the European Community under the BIOMED2 programme and the British Heart Foundation.

\section{REFERENCES}

1 Seger, R. and Krebs, E. G. (1995) FASEB J. 9, 726-735

2 Kyriakis, J. M. and Avruch, J. (1996) J. Biol. Chem. 271, 24313-24316

3 Cohen, P. (1997) Trends Cell Biol. 7, 353-361

4 Robinson, M. J. and Cobb, M. H. (1997) Curr. Opin. Cell Biol. 9, 180-186

5 Stokoe, D., Engel, K., Campbell, D. G., Cohen, P. and Gaestel, M. (1992) FEBS Lett. 313, 307-313

6 Rouse, J., Cohen, P., Trigon, S., Morange, M., Alonso-Llamazares, A., Zamanillo, D., Hunt, T. and Nebreda, A. R. (1994) Cell 78, 1027-1037

7 Bogoyevitch, M. A., Glennon, P. E. and Sugden, P. H. (1993) FEBS Lett. 317, $271-275$

8 Bogoyevitch, M. A., Glennon, P. E., Andersson, M. B., Clerk, A., Lazou, A., Marshall, C. J., Parker, P. J. and Sugden, P. H. (1994) J. Biol. Chem. 269, 1110-1119

9 Clerk, A., Bogoyevitch, M. A., Andersson, M. B. and Sugden, P. H. (1994) J. Biol. Chem. 269, 32848-32857

10 Bogoyevitch, M. A., Clerk, A. and Sugden, P. H. (1995) Biochem. J. 309, 437-443

11 Bogoyevitch, M. A., Andersson, M. B., Gillespie-Brown, J., Clerk, A., Glennon, P. E., Fuller, S. J. and Sugden, P. H. (1996) Biochem. J. 314, 115-121

12 Lazou, A., Bogoyevitch, M. A., Clerk, A., Fuller, S. J., Marshall, C. J. and Sugden, P. H. (1994) Circ. Res. 75, 932-941

13 Chien, K. R., Knowlton, K. U., Zhu, H. and Chien, S. (1991) FASEB J. 5, 3037-3046

14 Bogoyevitch, M. A. and Sugden, P. H. (1996) Int. J. Biochem. Cell Biol. 28, 1-12

15 Sheng, Z., Knowlton, K., Chen, J., Hoshijama, M., Brown, J. H. and Chien, K. R. (1997) J. Biol. Chem. 272, 5783-5791

16 Bogoyevitch, M. A., Ketterman, A. J. and Sugden, P. H. (1995) J. Biol. Chem. 270, 29710-29717

17 Ramirez, M. T., Sah, V. P., Zhao, X.-L., Hunter, J. J., Chien, K. R. and Brown, J. H. (1997) J. Biol. Chem. 272, 14057-14061

18 Knight, R. J. and Buxton, D. B. (1996) Biochem. Biophys. Res. Commun. 218, 83-88

19 Bogoyevitch, M. A., Gillespie-Brown, J., Ketterman, A. J., Fuller, S. J., Ben-Levy, R., Ashworth, A., Marshall, C. J. and Sugden, P. H. (1996) Circ. Res. 79, 161-172

20 Yin, T., Sandhu, G., Wolfgang, C. D., Burrier, A., Webb, R. L., Rigel, D. F., Hai, T. and Whelan, J. (1997) J. Biol. Chem. 272, 19943-19950

21 Johnson, N. L., Gardner, A. M., Diener, K. M., Lange-Carter, C. A., Gleavy, J., Jarpe, M. B., Minden, A., Karin, M., Zon, L. I. and Johnson, G. L. (1996) J. Biol. Chem. 271, 3229-3237

22 Park, D. S., Stefanis, L., Yan, C. Y. I., Farinelli, S. E. and Greene, L. A. (1996) J. Biol. Chem. 271, 21898-21905

23 Kawasaki, H., Morooka, T., Shimohama, S., Kimura, J., Hirano, T., Gotoh, Y. and Nishida, E. (1997) J. Biol. Chem. 272, 18518-18521

24 Park, J., Kim, I., Oh, Y. J., Lee, K.-W., Han, P.-L. and Choi, E.-J. (1997) J. Biol. Chem. 272, 16725-16728

25 Rudel, T. and Bokoch, G. M. (1997) Science 276, 1571-1574
26 Zechner, D., Thuerauf, D. J., Hanford, D. S., McDonough, P. M. and Glembotski, C. C. (1997) J. Cell Biol. 139, 115-127

27 Bradford, M. M. (1976) Anal. Biochem. 72, 248-254

28 Stokoe, D., Campbell, D. G., Nakielny, S., Hidaka, H., Leevers, S. J., Marshall, C. and Cohen, P. (1992) EMBO J. 11, 3985-3994

29 Smith, S. B. and Johnson, K. S. (1988) Gene 67, 31-40

30 Ben-Levy, R., Leighton, I. A., Doza, Y., Attwood, P., Morrice, N., Marshall, C. J. and Cohen, P. (1995) EMBO J. 14, 5920-5930

31 Papavassiliou, A. G., Treier, M. and Bohmann, D. (1995) EMBO J. 14, 2014-2019

32 Kameshita, I. and Fujisawa, H. (1989) Anal. Biochem. 183, 139-143

33 Lee, H. R., Henderson, S. A., Reynolds, R., Dunnmon, P., Yuan, D. and Chien, K. R. (1988) J. Biol. Chem. 263, 7352-7358

34 Iwaki, K., Sukhatme, V. P., Shubeita, H. E. and Chien, K. R. (1990) J. Biol. Chem. 265, 13809-13817

35 Han, J., Lee, J.-D., Bibbs, L. and Ulevitch, R. J. (1994) Science 265, 808-811

36 Lee, J. C., Laydon, J. T., McDonnell, P. C., Gallagher, T. F., Kumar, S., Green, D., McNulty, D., Blumenthal, M. J., Heys, R. J., Landvatter, S. W., et al. (1994) Nature (London) 372, 739-746

37 Cuenda, A., Rouse, J., Doza, Y. N., Meier, R., Cohen, P., Gallagher, T. F., Young, P. R. and Lee, J. C. (1995) FEBS Lett. 364, 229-233

38 Terzic, A., Pucéat, M., Vassort, G. and Vogel, S. M. (1993) Pharmacol. Rev. 45, $147-175$

39 Kramer, R. M., Roberts, E. F., Strifler, B. A. and Johnstone, E. M. (1995) J. Biol. Chem. 270, 27395-27398

40 El Benna, J., Han, J., Park, J. W., Schmid, E., Ulevitch, R. J. and Babior, B. M. (1996) Arch. Biochem. Biophys. 334, 395-400

41 Krump, E., Sanghera, J. S., Pelech, S. L., Furuya, W. and Grinstein, S. (1997) J. Biol. Chem. 272, 937-944

42 Zohn, I. E., Yu, H., Li, X., Cox, A. D. and Earp, H. S. (1995) Mol. Cell. Biol. 15, $6160-6168$

43 Wen, Y., Scott, S., Liu, Y., Gonzales, N. and Nadler, J. L. (1997) Circ. Res. 81 $651-655$

44 Shapiro, P. S., Evans, J. N., Davis, R. J. and Posada, J. A. (1996) J. Biol. Chem. 271, 5750-5754

45 Aquilla, E., Whelchel, A., Knot, H. J., Nelson, M. and Posada, J. (1996) J. Biol. Chem 271, 31572-31579

46 Bogoyevitch, M. A., Parker, P. J. and Sugden, P. H. (1993) Circ. Res. 72, 757-767

47 Pucéat, M., Hilal-Dandan, R., Strulovici, B., Brunton, L. L. and Brown, J. H. (1994) J. Biol. Chem. 269, 16938-16944

48 Rybin, V. 0. and Steinberg, S. F. (1994) Circ. Res. 74, 299-309

49 Clerk, A., Fuller, S. J., Michael, A. and Sugden, P. H. (1998) J. Biol. Chem. 273, 7228-7234

50 Jiang, Y., Chen, C., Li, Z., Guo, W., Gegner, J. A., Lin, S. and Han, J. (1996) J. Biol. Chem. 271, 17920-17926

51 Li, Z., Jian, Y., Ulevitch, R. J. and Han, J. (1996) Biochem. Biophys. Res. Commun. 228, 334-340

52 Cuenda, A., Cohen, P., Buée-Scherrer, V. and Goedert, M. (1997) EMBO J. 16 295-305

53 Goedert, M., Cuenda, A., Craxton, M., Jakes, R. and Cohen, P. (1997) EMBO J. 16 3563-3571

54 Jiang, Y., Gram, H., Zhao, M., New, L., Feng, L., Di Padova, F., Ulevitch, R. J. and Han, J. (1997) J. Biol. Chem. 272, 30122-30128

55 Kumar, S., McDonnell, P. C., Gum, R. J., Hand, A. T., Lee, J. C. and Young, P. R. (1997) Biochem. Biophys. Res. Commun. 235, 533-538

56 Wang, X. S., Diener, K., Manthey, C. L., Wang, S.-W., Rosenzweig, B., Bray, J., Delaney, J., Cole, C. N., Chan-Hui, P.-Y., Mantlo, N., et al. (1997) J. Biol. Chem. 272, 23668-23674

57 Lavoie, J. N., Lambert, H., Hickey, E., Weber, L. A. and Landry, J. (1995) Mol. Cell. Biol. 15, 505-516

58 Whitmarsh, A. J., Yang, S.-H., Su, M. S.-S., Sharrocks, A. D. and Davis, R. J. (1997) Mol. Cell. Biol. 17, 2360-2371

59 Lange-Carter, C. A., Pleiman, C. M., Gardner, A. M., Blumer, K. J. and Johnson, G. L. (1993) Science 260, 315-319

60 Fanger, G. R., Gerwins, P., Widmann, C., Jarpe, M. B. and Johnson, G. L. (1997) Curr. Opin. Gen. Dev. 7, 67-74

61 Dérijard, B., Raingeaud, J., Barrett, T., Wu, I.-H., Han, J., Ulevitch, R. J. and Davis, R. J. (1995) Science 267, 682-685

62 Lin, A., Minden, A., Martinetto, H., Claret, F.-X., Lange-Carter, C., Mercurio, F., Johnson, G. L. and Karin, M. (1995) Science 268, 286-290

63 Komuro, I., Kudo, S., Yamazaki, T., Zou, Y., Shiojima, I. and Yazaki, Y. (1996) FASEB J. 10, $631-636$

Received 14 January 1998/25 February 1998; accepted 12 March 1998 